\title{
Práticas psicológicas: enfrentamentos entre saúde pública e saúde coletiva
}

\author{
Anita Guazzelli Bernardes \\ Universidade Católica Dom Bosco \\ Neuza Maria de Fátima Guareschi \\ Universidade Federal do Rio Grande do Sul
}

\begin{abstract}
Resumo
Este artigo tem como objetivo problematizar as formas pelas quais a Psicologia se articula ao campo da saúde coletiva. O texto utiliza-se de uma estratégia genealógica, considerando as ferramentas foucaultianas de biopoder, verdade e subjetividade. O estudo reflete sobre as modificações das práticas psicológicas produzidas quando o fato psicológico deixa de ser um domínio do organismo para tornar-se um efeito da história de vida dos sujeitos. Essa transformação diz respeito à aproximação das práticas psicológicas do campo das políticas públicas de saúde. Entende-se que essa aproximação se conforma como um campo de lutas em que operam tanto uma lógica individualizante, quando as práticas psicológicas adéquam as políticas públicas a uma racionalidade tecnicista, tutelar e privatista, quanto uma lógica de militância na saúde, produzida pela adequação das práticas psicológicas ao direito e à cidadania.
\end{abstract}

Palavras-chave: práticas psicológicas; público; saúde coletiva.

\begin{abstract}
Psychological practices: confrontations between public health and collective health. This article aims at problematizing the ways through which Psychology articulates with the collective health field. We have employed a genealogical strategy, using Foucauldian analysis tools, such as bio-power, truth, and subjectivity. This study is a reflection on modifications of psychological practices produced when the psychological fact is no longer an organism domain, becoming an effect of the subjects' life history. Such change concerns the approximation of psychological practices to the field of public health policies. This approximation is understood as a battlefield in which both individualizing logic and the logic of health militancy operate; the former is present when psychological practices fit public policies into a technical, tutelary, private rationality, and the latter is produced through conformity of psychological practices to both right and citizenship.
\end{abstract}

Keywords: psychological practices; public; collective health.

A psicologia, em contrapartida, nasce neste ponto no qual a prática do homem encontra sua própria contradição (Foucault, 2002b, p. 134).

Este artigo tem como objetivo problematizar as formas pelas quais a Psicologia se articula ao campo da saúde coletiva. Entretanto, para refletir sobre a aproximação das práticas psicológicas com o campo da saúde coletiva, torna-se importante percorrer um solo em que a saúde se torna pública para então metamorfosear-se em coletiva. A leitura não é linear, e sim genealógica, o que faz o olhar mover-se na direção de acontecimentos/descontinuidades. Esta reflexão é feita mediante a utilização do público como conceito-problema da linha de argumentação. Para tanto, o público é considerado um dispositivo no campo da saúde, um dispositivo de publicização ${ }^{1}$. O texto utiliza como ferramentas de análise os conceitos de biopoder, verdade e subjetividade (Foucault, 1995a).
O exercício deste estudo foi, em um primeiro momento, refletir sobre o público como um dispositivo, no sentido de torná-lo um conceito-problema que se conforma segundo um conjunto heterogêneo de saberes e um jogo de forças que adquire certa tonalidade em razão das articulações que o tornam visível e enunciável, como no caso do campo da saúde. O dispositivo de publicização conforma a relação entre Estado, saúde e trabalho como modo de governamentalidade da "questão social". O dispositivo de publicização responde à urgência da "questão social" no século XX no Brasil, em função de novos ordenamentos sociais constituídos pela industrialização urbanização, pobreza, epidemias - que criam a necessidade de uma razão de Estado. Esta discussão aborda as implicações que as modificações das práticas psicológicas trazem para o campo da saúde quando se migra da relação entre organismo/psiquismo para a relação entre história/psiquismo e como essa metamorfose 
estabelece certa configuração do público na saúde, tornando-se parte desse dispositivo. Essa metamorfose foi dividida em dois campos de discussão sobre as práticas de governo forjadas pela Psicologia: economia psíquica e saúde pública; reformatórios e ressocialização psíquica. Em um segundo momento, analisou-se os efeitos dessa metamorfose das práticas psicológicas quando articuladas à política: o campo de reflexão é Psicologia, saúde e política, considerando os enfrentamentos entre uma política de individualização e a militância política, ou seja, quando a saúde coletiva provoca novas estratégias de poder na Psicologia. $\mathrm{O}$ texto é finalizado com uma prática de reflexão sobre a relação, no contemporâneo, entre Psicologia e saúde coletiva.

\section{O público como conceito-problema para o público como um dispositivo}

A análise deste texto parte da forma como a saúde pode ser compreendida a partir do momento em que é colocada como correlata do público, em razão de certo momento e de certos processos de vulnerabilidade decorrentes de uma racionalidade privada - a saúde pública. As condições de possibilidade dessa articulação da saúde com o público emergem na modernidade: por um lado, os crescentes processos de urbanização decorrentes da Revolução Industrial, a formação de Estados-Nação e a posterior perspectiva de progresso de cada uma dessas nações; por outro lado, pobreza/trabalho/epidemias como uma "questão social" a ser considerada como problemática de Estado.

Com isso, considera-se que na modernidade o público, ao contrário da experiência greco-romana, que o conformava como uma esfera relativa a um espaço comum de trocas entre homens livres, torna-se um campo de lutas. Nele se atravessam, por um lado, a medicina social, a polícia e a figura jurídica do Estado; por outro, movimentos de resistência, tais como a organização operária e os conflitos urbanos originados por fome e miséria. Isso engendra um campo de visibilidade e dizibilidade, bem como de controle e produção de subjetividades, implicando um dispositivo de publicização.

A compreensão do público como dispositivo parte das proposições de Foucault (1999) sobre o conceito. Por dispositivo de publicização, entende-se um campo de lutas/jogos de força envolvendo um conjunto heterogêneo de práticas discursivas que respondem à "questão social" emergente na modernidade. O público, então, produz a figura do indivíduo privado, e não do sujeito que se dá a conhecer por meio das relações de troca e filiação social (Castel, 2003). Ao equalizar pobreza/trabalho/ epidemias, o público constitui-se como um território que filia o desfiliado à saúde, não em termos de práticas de liberdade, mas de práticas de recrudescimento da miséria humana, na medida em que a saúde se torna objeto de controle e regulação da população em seu conjunto. $\mathrm{O}$ território de experiência que se produz pelo dispositivo, ao mesmo tempo em que individualiza as condições de vida, torna-as dependentes, investindo em uma relação de tutela e regulação das formas de desfiliação social. O público não se interessa pela desfiliação, mas pela forma como o poder possibilita o investimento na desfiliação que funciona no interior do sistema político-econômico, ou seja, na sua rentabilidade e utilidade política. Controle, regulação, rentabilidade e utilidade, como estratégias de governo, acabam por tornar a saúde das populações um objeto imprescindível de articulação e ação.

Com base nessas reflexões, o público passa a ser um conceito-problema, pois é mediante a análise deste que se torna possível a conformação do campo da saúde pública. A articulação entre o público e a saúde é possível pela emergência desse dispositivo, ou seja, quando se produz certa experiência em que o público deixa de ser espaço de trocas, mercado de trocas e de reconhecimento, surgindo como um conjunto de estratégias políticas e discursivas que fazem dele um dispositivo de investimentos que objetiva, entre outros elementos, a saúde das populações.

A saúde, então, quando objetivada pelo público, deixa de ser parte de um conjunto de práticas de cuidados de si para o exercício político - como na experiência greco-romana, um dos elementos das artes de governo de si e do outro -, para entrar em um território de regulação da vida, no sentido de fazer viver ou deixar morrer (Foucault, 1999). A partir disso, a questão não é tomar o público como uma evidência no campo psicológico, mas o modo como a racionalidade individualizante/adaptativa das práticas psicológicas torna-se uma oferta de serviços para um dispositivo que investe no controle das formas de desfiliação/ filiação social. Essa discussão ampara-se na leitura que Foucault (2002b) faz da Psicologia:

Sem forçar uma exatidão, pode-se dizer que a psicologia contemporânea é, em sua origem, uma análise do anormal, do patológico, do conflituoso, uma reflexão sobre as contradições do homem consigo mesmo. E se ela se transformou em uma psicologia do normal, do adaptativo, do organizado, é de um segundo modo, como que por um esforço para dominar essas contradições. (p. 135)

\section{Práticas psicológicas: do organismo para a história}

A ciência psicológica integra-se ao campo da saúde no momento em que seu campo de compreensão, transposto das ciências físico-naturais, em que as leis da natureza explicavam o fenômeno humano, encontra-se com as relações que os humanos travam consigo mesmos e com os outros, escapando às leis da natureza. A compreensão do humano como tal - não apenas como um ser vivente - será construída pela relação entre o humano e a história que o constitui. Esse procedimento objetiva uma condição humana na própria natureza humana. A objetivação da condição humana pelas práticas psicológicas implica migrar dos espaços artificiais de laboratórios para o ambiente e para a história (Foucault, 2002b).

Os exercícios da Psicologia, de ser vivente para ser humano, apresentam distintas operações na produção do sujeito psicológico. O sujeito psicológico como ser vivente é objetivado como aquele que faz parte de um processo de evolução dos seres vivos no que tange à seleção natural - aquele mais apto em termos de aparato neurológico. Esse sujeito é compreendido em um vácuo, porque as condições de sua existência são explicadas pelo desenvolvimento dos seres vivos, e não dos seres humanos, ou seja, em um primeiro momento, as práticas psicológicas objetivam um humano como organismo que se desenvolve à mercê da história e das relações que o circundam. O processo de desenvolvimento é individual. Não há, nessa racionalidade, 
uma relação entre humanos, e sim entre seres vivos na busca de sobrevivência. As práticas psicológicas são voltadas para uma topologia cerebral, para aquilo que torna o humano uma espécie mais evoluída. $\mathrm{O}$ ambiente, neste caso, é considerado como espaço geográfico onde a vida se desenrola e local de lutas pela sobrevivência por meio de princípios adaptativos.

$\mathrm{O}$ que se quer apontar com isso é que, nessa configuração do campo psicológico, não é possível formular uma experiência privada, nem tampouco uma experiência pública. A possibilidade de aproximação é quando o privado se equaliza a uma topologia cerebral, ou seja, o privado torna-se sinônimo de mental. Isso, seguindo os rastros de Foucault (2002b), é o que cria para a Psicologia uma problemática: a noção de evolução do humano colada ao seu aparato cerebral/mental. Assim, a possibilidade de uma topologia cerebral mais desenvolvida caracterizaria o apogeu da espécie humana como ser vivo. Entretanto - e aí emerge uma problemática -, essa topologia, quando apreendida pela memória, é o que causa, na compreensão do humano, uma contradição, pois o evolucionismo

mostra que o fato psicológico não tem sentido senão com relação a um futuro e a um passado, que seu conteúdo atual assenta-se sobre um fundo silencioso de estruturas anteriores que o carregam de toda uma história, mas que ele implica, ao mesmo tempo, um horizonte aberto sobre o eventual. (Foucault, 2002b, p. 138)

A relação com a percepção de um passado e um futuro tornase uma condição de possibilidade de as práticas psicológicas migrarem o fato psicológico para o plano das significações que o humano constitui mediante uma história de vida.

Esse plano que começa a engendrar-se coloca a Psicologia na direção da produção de um sujeito dotado de um mundo interno, de um mundo de representações que forja a figura do sujeito privado. $\mathrm{O}$ sujeito privado difere do sujeito privado da economia política (Foucault, 2003). Não se trata de localizar essa experiência do privado, em um primeiro momento, no âmbito da economia doméstica, no âmbito do lar, e sim de localizá-lo em um espaço interior, um espaço dentro do sujeito, não específico da atividade cerebral, do organismo do ser vivo, mas específico da condição humana, de sua relação com o passado e com o futuro. Trata-se de examinar o humano naquilo que o difere das noções de natureza: a experiência de interioridade.

A formulação de interioridade é a possibilidade de a Psicologia aproximar-se do campo da saúde, na medida em que o fato psicológico, como experiência interna, apresenta os descaminhos do humano em relação ao processo de desenvolvimento natural do ser vivo. São os fenômenos de adoecimento que empurram a Psicologia para uma ciência humana, e não natural. Os fenômenos de adoecimento serão considerados na sua articulação com um plano de representações e significações mentais que formulam, de um lado, a estrutura do sujeito psicológico, figuras neuróticas, psicóticas, perversas; de outro lado, a relação dessa estrutura com aquilo que é exterior à interioridade do sujeito: a família. De acordo com Rose (2001a), essa produção das práticas psicológicas interpela o sujeito como um eu dotado de uma subjetividade interna e individualizada, um sujeito em profundidade que circunscreve o seu próprio eu pelo "envelope da pele" (Rose, 2001a, p. 144). A emergência da interioridade no campo psicológico tornar-se-á um objeto das formas de governo das vidas. Essa dimensão interior formada pelas relações familiares, articuladas pela psicopatologia, abre um espaço de investimento governamental sobre a interioridade e a família.

As formas de governo da interioridade e da família tornamse possíveis porque se aliam aos ideais modernos da saúde como uma questão de polícia (Foucault, 1995a). A Psicologia contribui nesse agenciamento com a formulação de um eu interior que, mediante o controle de si e da família, se torna regulável, adaptável. São os fenômenos de adoecimento que possibilitam a formulação de uma interioridade que reformula as práticas psicológicas, de modo a entrar na esteira das práticas disciplinares e biopolíticas. Dessa forma, as práticas psicológicas tornam-se um elemento operativo no interior dos jogos de biopoder.

Poder-se-ia pensar, então, que essa entrada via psicopatologia no campo do biopoder seria uma forma de a Psicologia tornarse mais um dos elementos do dispositivo de publicização? $\mathrm{O}$ que ocorre é a Psicologia nutrir-se das problematizações do público como experiência de pobreza e tutela para solidificar e territorializar uma experiência do privado. A Psicologia apresenta-se como uma possibilidade de salvaguardar individualidades, na medida em que é nessa figura de indivíduo que investe; é a possibilidade de objetivação do indivíduo que dá à Psicologia um status, um regime de verdades.

\section{Economia psíquica e saúde pública: intensificação da privatividade}

O processo de objetivação da saúde, no campo da Psicologia, parte das disfunções individuais para os efeitos destas no conjunto da população. As práticas de governo "psi” forjam o privado/interno e justificam-no como forma de proteção do conjunto da população. Nesse sentido, a saúde pública, como formulada pela medicina social, não é objeto da Psicologia, na medida em que o que está em jogo é a saúde do indivíduo. A maneira de a Psicologia subsidiar os jogos de biopoder diz respeito à intensificação da privatividade do indivíduo por meio de práticas e procedimentos que o tornam não apenas responsável pelos processos de adoecimento, mas que o mantêm responsabilizável. Essa manutenção do responsabilizável tornase um dos mecanismos biopolíticos da Psicologia.

Esse mecanismo será articulado no interior do espaço doméstico, daquilo que se estabelece como família nuclear. A família nuclear é a via pela qual se torna possível objetivar uma economia psíquica. É por meio do governo (práticas de exame e confissão, tribunal de condutas, condicionamentos) da economia psíquica que a Psicologia começa a tornar-se uma estratégia de controle das populações. A economia psíquica é a forma pela qual as práticas psicológicas inscrevem o eu individualizado e interiorizado como a base de uma narrativa histórica. Isso implica voltar-se para os efeitos dessa economia no que tange à problemática da conduta do sujeito sobre si mesmo ou sobre os outros. A inteligibilidade e a visibilidade que as práticas psicológicas produzem possibilitam tanto a necessidade de administração da economia psíquica quanto 
a forma personalizada como será administrada. A economia psíquica será uma das formas de a Psicologia articular-se à saúde pública no que tange às tecnologias do eu despóticas e epistemológicas (Rose, 2001b). Por tecnologias despóticas, esse autor compreende as formas de controle de si mesmo (controlar ação, controlar afeto, controlar fantasias). Por tecnologias epistemológicas, entende-se a relação que o sujeito é levado a ter consigo mesmo em termos de conhecimento de si, mediante a conformação de um "eu". Poder-se-ia pensar que se essas tecnologias apareciam nas práticas gregas analisadas por Foucault (1987) como constitutivas de uma substância ética, o que as diferenciaria das práticas psicológicas modernas? A diferença encontra-se na questão de que os gregos não tinham a formulação de um eu soberano e privado; as tecnologias de si eram estratégias para constituir-se como um sujeito político, não como um eu privado, administrado por uma ética normativa. A ética normativa das práticas psicológicas será possível pela articulação da economia psíquica com a epidemiologia psíquica.

O que possibilita a Psicologia tornar-se um mecanismo de poder são, justamente, as condições de sua emergência: uma sociedade de normalização. É por meio da norma que se investirão tecnologias de governo tanto em um corpo individual quanto em uma população; é por meio da norma que se abre para as práticas psicológicas um espaço de expressão na economia política (Foucault, 2005). A relação com a economia política diz respeito à formulação de um sujeito governável pela política, um eu privado, elemento de uma população, administrável por meio de uma economia psíquica, e não como o faziam os gregos, que objetivavam a relação entre economia política e sujeito político. $\mathrm{O}$ instrumento de normalização é encontrado nas práticas de higiene mental.

\section{Intensificação da privatividade e integração ao público}

A Psicologia integra-se ao território público, à experiência de público, mediante uma epidemiologia psíquica administrada pela higiene mental. Os serviços de higiene mental, segundo Bleger (1984), é que ampliam as práticas psicológicas, migrandose do espaço reservado dos consultórios para o espaço da saúde pública:

A função social do psicólogo clínico não deve ser basicamente terapia e sim a saúde pública e, dentro dela, a higiene mental. O psicólogo deve intervir intensamente em todos os aspectos e problemas que concernem à psico-higiene e não esperar que a pessoa adoeça para recém intervir. (Bleger, 1984, p. 20)

As práticas psicológicas na saúde pública formulam-se como profilaxia e pedagogia dos comportamentos da vida cotidiana baseadas em uma interioridade. Dessa forma, as práticas psicológicas constituem um status e um lugar na saúde pública mediante a elaboração de um projeto de investimentos biopolíticos, tornando o profissional psicólogo um elemento constitutivo do que se elabora como público.

A história e as formas de significação serão coladas aos comportamentos do cotidiano por meio da psico-higiene, engendrando uma articulação do indivíduo privado com o dispositivo de publicização - um público forjado pela conduta diária da população em seu conjunto:
O psicólogo clínico deve sair em busca de seu cliente: a pessoa no curso de seu trabalho cotidiano. O grande passo em psicohigiene consiste nisto: não esperar que a pessoa doente venha consultar e sim sair a tratar e intervir nos processos psicológicos que gravitam e afetam a estrutura da personalidade e - portanto - as relações entre os seres humanos, motivando com isso o público para que possa concorrer a solicitar seus serviços em condições que não impliquem doença. Isto abre uma perspectiva ampla e promissora para a saúde da população e uma fonte de profunda gratificação para o profissional. (Bleger, 1984, p. 27)

Isso significa uma metamorfose no campo psicológico, pois, em uma primeira conformação, organizava-se em duas fronteiras: o dentro (mental, psíquico) e o fora (ambiente/sociedade). $\mathrm{Na}$ saúde pública, as práticas psicológicas permitem operacionalizar outra fronteira: o público e o privado, objetivando o primeiro como população/pobreza/Estado organizados em comunidades periféricas e o segundo como o eu interior envelopado pela pele. A objetivação desse espaço dá-se nos serviços de higiene mental por meio da profilaxia das condutas e do cotidiano, ou seja, as práticas psicológicas começam a entrar no cotidiano das comunidades mediante tecnologias de equilíbrio social. $\mathrm{O}$ equilíbrio social será administrado a partir de dois domínios pelas práticas psicológicas: os reformatórios psíquicos e as ressocializações psíquicas.

\section{Refomatórios e ressocializações psíquicas: a arte de governar das práticas psicológicas}

Os reformatórios psíquicos dizem respeito à gama de práticas de clausura, sejam elas manicomiais, educativas, prisionais ou industriais, que encontram nas terapêuticas sua forma de controle. Terapêutica não no sentido estrito de psicoterapia, mas

no sentido de que a relação consigo mesmo é, ela própria,
dobrada em termos terapêuticos - problematizando a si
mesmo de acordo com valores de normalidade e da patologia,
diagnosticando nossos prazeres e desgraças em termos psi,
buscando retificar ou melhorar nossa existência cotidiana por
uma intervenção em um mundo interior que temos dobrado
como sendo tanto fundamental para a nossa existência como
humanos quanto, entretanto, tão próximo à superfície de nossa
experiência do cotidiano. (Rose, 2001a, p. 188)

As figuras formuladas por essas práticas são os indivíduos que não cessam de aparecer nas populações: as crianças e os jovens, os psicopatológicos, os criminosos e suas vítimas, os subversivos, os operários. Os reformatórios psíquicos investem no indivíduo privado. Assim, as práticas de privação vêm ao encontro dessa figura para reforçá-la e responsabilizá-la. O privado torna-se uma condição para salvaguardar o público, para este não ser contaminado (Coimbra, 1995).

A ressocialização psíquica é a forma pela qual as práticas psicológicas se voltam para os fenômenos de população, configurando-se como uma biopolítica: pobreza, natalidade, mortalidade, habitação. O fenômeno da vida, no campo psicológico, é objetivado a partir das condutas expressas no cotidiano, produzidas por um aparato psíquico, interno. 
A ressocialização psíquica é a tecnologia mediante a qual as práticas psicológicas sobem "os morros", migrando dos espaços de privação. Aquilo que é retirado dos espaços do cotidiano precisa ser reintegrado, precisa ser ressocializado. A ressocialização investe no cotidiano da população em termos de regras de conduta. $\mathrm{O}$ foco não é propriamente o interior do sujeito, mas a forma de manifestação desse interior em termos de comportamento, de conduta, de hábitos diários, um território onde a saúde do indivíduo se torna inteligível e praticável segundo um modelo de equilíbrio social. Aqui a operação é sobre as práticas de saúde, de higiene social, de adaptação às condições de vida.

Dessa forma, trabalha-se não com a problematização do público, mas com a adaptação do indivíduo privado ao público, como apontam Dimenstein (1998), Spink (2003), Spink e Matta (2007), no que tange à inserção das práticas psicológicas na saúde pública no Brasil. As práticas psicológicas transpõem um modelo clínico/privatista/assistencialista para a saúde pública. Esse movimento das práticas psicológicas não significa a conformação de um campo de reflexão sobre o que produzem, tampouco o que as políticas de saúde conformavam até o início da década de 1980, e sim uma submissão do território da saúde pública ao rol de tecnologias da própria Psicologia. Essa inserção acaba por reforçar um modelo de saúde assistencialista/privatista organizador do sistema de saúde no país até o final da década de 1970 (Campos, 2009). Nessa racionalidade, torna-se importante mostrar para a população que, se as condições de sua vida são precárias, é porque não houve um investimento privado para modificá-las; desse modo, trata-se de uma questão de escolhas pessoais. As enunciações psicológicas articulam-se à economia política, incitam à experiência de que pobreza, seja ela "material ou espiritual", é uma questão individual.

Os exercícios das práticas psicológicas operam com uma racionalidade que recrudesce a figura do eu privado, objetivando-o em termos de elemento/indivíduo da população e, ao mesmo tempo, o caracteriza como um eu precarizado, empobrecido. Assim, a supremacia do indivíduo privado, nas práticas psicológicas, é correlata da fragilidade desse eu em termos de economia psíquica. Essa fragilidade sustenta a necessidade perene da figura do expert, da autoridade, do outro não como alteridade, mas como elemento regulatório dessa fragilidade. As práticas psicológicas não se voltam especificamente para os fenômenos da pobreza como característica de processos sociais forjados pelo capitalismo. As práticas psicológicas ocupam-se da pobreza psíquica do indivíduo privado e a formulam. Essa pobreza psíquica, que leva o sujeito indivíduo/privado a atos de conduta que desorganizam o tecido social, justifica a necessidade da tutela.

A tutela, conjuntamente com a higiene mental, é o solo das práticas psicológicas na saúde pública. No espaço das práticas psicológicas, a saúde pública é formulada como controle da pobreza psíquica, pois da doença, da psicopatologia, o sujeito privado nunca está livre. Trata-se de uma subjetividade que carece de ideais de economia psíquica: pai alcoolista e desempregado; mãe prostituta e empregada doméstica; pais e mães ausentes; pais violentos e mães submissas; mães que se tornam pais e pais que desaparecem; famílias desestruturadas.
A tutela permite que esse indivíduo privado seja governável para compreender que sua história repetirá a história de seus pais, portanto, deve responsabilizar-se em controlar essas faltas internas para modificar a sua história.

A Psicologia oferece para a saúde pública a interioridade do sujeito público e a racionalidade técnica para seu governo. Potencializa, dessa forma, um modelo de saúde produzido pelo dispositivo de publicização, em que as estratégias políticas se voltam para o combate às epidemias/endemias e à saúde como ausência de doença, corolário do desenvolvimento econômico e benesse social, mediante o controle e a regulação da população a partir do esquadrinhamento social (Campos, 2009). De que modo, então, as práticas psicológicas constituirão o enfrentamento entre saúde pública e saúde coletiva, que passam de uma inteligibilidade da saúde como ausência de doença para a saúde como uma questão plural?

\section{Psicologia, saúde e política}

Discutir o modo como a Psicologia entra na esteira dos enfrentamentos entre a saúde pública e a saúde coletiva implica pensar que problemáticas se apresentam como contradições no campo psicológico para se formular outra racionalidade. Como o dispositivo de publicização opera modificações dentro do campo da Psicologia, alinhando-a à problemática da saúde coletiva? Dois eixos são objetivados nesta discussão: a fragmentação do "eu" privado e a política como analisador das práticas psicológicas.

A fragmentação do eu privado anuncia-se no campo psicológico por meio da proliferação de teorias que o objetivam. As problemáticas com as quais as práticas psicológicas se encontram, a partir daquilo mesmo que produzem, determinam modificações teórico-metodológicas. A soberania do eu não cessa de defrontar-se com aquilo que o fragiliza: a vida como fato e como forma. Segundo Rose (2001a), novas imagens de subjetividade são agenciadas: socialmente construída, dialógica, inscrita na superfície do corpo, espacializada, nômade, descentrada.

$\mathrm{O}$ eu passa a ser mais um dos equipamentos constitutivos dessas subjetividades, e não apenas o equipamento. Isso não quer dizer que a Psicologia abandona o eu privado, mas que se intensificam as formas de governo sobre ele. Essa intensificação ocorre mediante a produção de um eu como a base narrativa da história, "como locus de direitos e reivindicações legítimas, como um ator que busca empresariar sua vida e seu eu por meio de escolha" (Rose, 2001a, p. 140). Essa racionalidade prática de empresariar a própria vida traz consigo um campo de lutas relacionadas às formas de sujeição da subjetividade, ou seja, aquilo que se torna efeito das tecnologias "psi": o empreendedorismo e a responsabilidade sobre si mesmo agenciam efeitos de resistência. Essas formas de resistência não são uma grande recusa, como assinala Foucault (1995b), mas uma derivada do próprio campo, um movimento centrífugo.

Esse movimento centrífugo aproxima mais uma vez a racionalidade "psi" da política. Aproxima mais uma vez porque já havia uma composição, na medida em que as práticas psicológicas, ao tornarem-se uma forma de o poder exercer-se sobre a vida, uma biopolítica por meio dos reformatórios e 
ressocializações psíquicas forjavam, conjuntamente com outras tecnologias de governo, uma política de individualização. Contudo, a aproximação agora ocorre por meio de uma militância política. A militância política é uma forma de inflexão das linhas de força que colocam as próprias práticas psicológicas em análise. Do eu privado, a Psicologia parte para a reflexão sobre as tecnologias que produz e que investe nessa privatização e individualização do eu. É um movimento de estranhamento dentro do próprio campo e engendra outra problemática para as práticas psicológicas: por um lado, a afirmação da diferença, da multiplicidade de histórias de vida e dos modos de singularização; por outro lado, a captura dessas diferenças em termos de identidades, de marcadores que cindem o tecido social e fragmentam a vida coletiva (Coimbra, 2002).

\section{Política de individualização e militância política}

A problemática que se engendra entre política de individualização e militância política coloca as práticas psicológicas não apenas na esteira das formas de governo da população, mas na das discussões sobre as próprias formas de governo da população. Da economia psíquica, parte-se para a economia política. Do indivíduo como elemento constitutivo da população, formula-se a questão da população como um coletivo de forças que forjam diversos status, lugares e posições a serem ocupados em regimes particulares para que algo se torne inteligível e operável (Foucault, 2000).

Esses regimes particulares produzem, no campo psicológico, outra racionalidade, outra forma de inteligibilidade, voltada para os dispositivos que edificam e mediam a relação que o humano estabelece consigo mesmo. A analítica de dispositivos também possibilita às práticas psicológicas ascender à saúde coletiva. Em um regime em que saúde é tomada como ausência de doença, cabe às práticas psicológicas tomar o fato psicológico por meio de uma economia psíquica e justificar um plano de ações a partir de um dispositivo que formula um sujeito público/ indivíduo incapaz de gerir a si mesmo. Por outro lado, ligar as práticas psicológicas a um regime de verdade em que a saúde é considerada como uma questão plural e tributária da organização social de um país (Lei $\mathrm{n}^{-}$8.080/90) cria a necessidade da fabricação de outro sujeito psicológico, ou seja, implica tanto a necessidade de problematizar os dispositivos que fabricavam a experiência de um sujeito público/indivíduo, quanto à construção de outros dispositivos que modifiquem essas subjetividades, de modo a fragmentar o sujeito das práticas psicológicas.

A forma pela qual a Psicologia se encontra com a política é herdeira do Movimento da Luta Antimanicomial. Dessa forma, o adoecimento também é a via pela qual a Psicologia entra em outra esteira discursiva, de forma a considerar a loucura não apenas em relação à experiência que o sujeito louco faz de si mesmo, mas também que ela apenas é possível em uma sociedade - "ela não existe fora das normas da sensibilidade que a isolam e das formas de repulsa que a excluem ou a capturam" (Foucault, 2002a, p. 163). A demarcação de um território psicológico é fundamental para a Psicologia considerar que um determinado regime discursivo, como o da saúde, também faz parte de seu repertório. Desse modo, voltar-se para a saúde mental assegura às práticas psicológicas um status, um lugar e uma posição inteligível e operável, pois ali está a zona privada de seus investimentos: o sujeito psíquico. Entretanto, será um sujeito ora da saúde mental, ora da militância política, de acordo com o modo como for capturado/produzido pelas práticas psicológicas.

É a partir dessa relação entre zona privada das práticas psicológicas com militância política da Reforma Psiquiátrica que o sujeito psíquico constitutivo do sujeito público/indivíduo se fragilizará, fragmentando-se em outras figuras existenciais. Dessa maneira, integrar-se ao movimento de Reforma Psiquiátrica produz nas práticas psicológicas a necessidade de novas articulações, que se encontram principalmente no território da reflexão sobre o modo como um modelo clínico/privatista/ assistencialista corrobora a produção de desigualdades sociais e restos da existência significados como vidas menos dignas. Os restos da existência característicos da lógica manicomial serão articulados à racionalidade do dever e do direito, produzidos na Constituição de 1988, e do fortalecimento do campo dos Direitos Humanos. A inteligibilidade da saúde como um dever do Estado e um direito de todo cidadão brasileiro abre para as práticas psicológicas outro território: o das políticas públicas. Esse território não diz respeito ao trabalho especificamente na rede pública, mas à participação na formulação das políticas que operacionalizam as ações na rede pública:

No que se refere às articulações das entidades da categoria, encontramos o registro de 1985, quando o Conselho Regional de Psicologia, a Sociedade de Psicologia e o Sindicato dos Psicólogos do Rio Grande do Sul constituíram uma Comissão de Saúde que buscava conhecer o trabalho dos profissionais de Psicologia na saúde (Comissão de Saúde Interentidades, 1985/1986). Esta tinha como cenário a discussão de uma Política Nacional de Saúde e a demanda para participação em Conferências e Comissões Interinstitucionais, potencializadas com o Movimento da Luta Antimanicomial. (Nascimento, 2004, p. 11)

O campo de lutas que se conforma na Psicologia diz respeito à operacionalização desse sujeito privado/psíquico com o sujeito do direito e do dever. Se, em um primeiro momento, as práticas psicológicas subsidiam as formas de o poder se exercer sobre a vida ao objetivarem o elemento constitutivo da população - o sujeito privado -, em um segundo momento, as práticas psicológicas defrontam-se com os efeitos desse sujeito em termos de práticas de liberdade. O sujeito privado agenciado pelo dispositivo de publicização, ao deparar-se com o sujeito de direito da reforma sanitária (Campos, 2009), provoca a Psicologia a investir não apenas em uma interioridade, mas no campo de relações em que as interioridades aparecem para além dos reformatórios psíquicos: as potências de heterogeneização dos coletivos. O sujeito de direito é uma derivada do sujeito político que emerge da saúde coletiva (Macedo \& Dimenstein, 2009): a produção de um sujeito político em termos de cidadania mobiliza-o em relação ao Estado. Como as práticas em saúde que se produzem voltam-se para as formas de captura desse sujeito político e para o investimento no sujeito tutelado nos enfrentamentos entre um discurso da saúde pública e um discurso da saúde coletiva, os jogos que encontramos nas práticas psicológicas articulam esse enfrentamento.

Tais contradições apresentam-se na própria formação 
em Psicologia a partir da década de 1990 (Bernardes, 2006; Guareschi, Dhein, Reis, Machry, \& Bennemann, 2010), de modo que os currículos contemplam tanto um processo de subjetivação voltado para uma lógica interna/privada, subsidiada por nosografias psiquiátricas e seus desdobramentos em termos de psiconeurologia, psicofarmacologia e psicossomática, quanto uma lógica subsidiada pela Reforma Psiquiátrica. O plural da saúde nas práticas psicológicas da formação de psicólogos não se encontra propriamente naquilo que se estabelece constitucionalmente a partir de 1988. A saúde coletiva não entra nos currículos produzindo uma modificação na estrutura de formação, na medida em que se torna uma disciplina opcional e não um eixo conformador das práticas psicológicas, assim como aconteceu com a Reforma Psiquiátrica, que aparece como disciplina, e não como racionalidade constitutiva das práticas psicológicas. Os efeitos da incorporação da reforma sanitária como discurso constitutivo e reflexivo das práticas psicológicas encontram-se no modo de objetivação da saúde como uma questão integral e plural. Entretanto, a problemática do plural na formação em Psicologia diz respeito à gama de inteligibilidades que definem a saúde pelo comportamento adaptado, a saúde pela ausência de sintomas, a saúde como condições de trabalhar, a saúde como condições de aprender, a saúde como bem-estar da comunidade, e não como princípio das práticas em saúde. A integralidade implica considerar que a experiência privada do sujeito opera marcas em seu corpo, ou seja, a existência de um paralelismo psicofísico novamente não é desenhada como diretriz das políticas públicas de saúde ao ser reduzida à experiência privada, e não a vínculo, horizontalização e interssetorialização dos serviços, demandas espontâneas e políticas específicas.

\section{Psicologia e saúde coletiva: articulações para práti- cas de reflexão}

Essas contradições constitutivas das práticas psicológicas sujeito privado e sujeito de direito/cidadão - operam no campo psicológico um embate político, um jogo de força que tenta a todo o momento tornar a saúde uma evidência ou um problema: evidência quando tomada como fato psicológico; problema quando formulada como forma de vida. Esse enfrentamento torna-se útil para o dispositivo de publicização, na medida em que as regras de existência para os objetos que se encontram nomeados, descritos, designados nesse território são leis de possibilidade para as relações afirmadas ou negadas no campo da saúde. Tais relações referem-se às formas de intervenções psicológicas, que operam tanto na interioridade do sujeito/ indivíduo/privado, sendo consideradas necessárias para delimitar o domínio das práticas psicológicas no que tange à evidência do fato psicológico, quanto na problematização perene das formas de subjetivação pela saúde, quando transversalizadas pelo discurso da saúde coletiva. Esses exercícios de fragmentação criam as condições de racionalidades que justificam uma série de ações que vão ao encontro da saúde pública ou da saúde coletiva, mas que, no entanto, não são excludentes, na medida em que se misturam no cotidiano (Macedo \& Dimenstein, 2009).

Essa mistura é agenciada pelas diferentes formas de compor um sistema de saúde. A necessidade que se cria de tornar os direitos universais pulveriza esses direitos em categorias identitárias e em programas de saúde específicos para cada grupo que compõe as comunidades. Desse modo, as práticas psicológicas, ao tornarem uma evidência as diversas formas de vida, acabam por incitar uma racionalidade de direito específica a cada taxionomia social: programas voltados para a saúde da mulher, desdobrados em gestantes, adolescentes gestantes, vítimas de violência doméstica, mulheres oncológicas, etc.; programas voltados para DST/AIDS, desdobrados em homossexuais, drogaditos, mulheres casadas, adolescentes, prostitutas, etc.; programas voltados para educação em saúde, desdobrados em coleta de lixo, reciclagem de lixo, utilização da água, utilização de medicamentos, cuidados com a alimentação, etc. Essa gama de objetos encontra suas possibilidades de aparecimento na saúde coletiva no que tange a relação entre equidade, universalidade e hierarquização das políticas de saúde, mas a necessidade de personalização é tributária também da racionalidade da saúde pública quando esquadrinha o tecido social a partir de perfis epidemiológicos e estratégias que investem no fazer viver ou no deixar morrer.

O que se quer apontar com isso é que a publicização das práticas psicológicas atualiza a saúde pública como mais um dos territórios de intervenção psicológica dentro da racionalidade do público; este sendo restos da existência e do indivíduo, como elemento governável desse território (Dimenstein, 1998). Assim, a lógica de saúde que fundamenta as práticas psicológicas encontra-se como ausência de doença e presença de equilíbrio social. A saúde coletiva entra como uma derivada das práticas em saúde pública e torna-se um elemento do encontro da Psicologia com a política, embora não em termos de uma modificação da racionalidade do público, da saúde e da população, e sim como uma forma de resistência, de práticas reflexivas que a todo o momento convocam novas formas de o poder se exercer. Há, então, um exercício constante de reforma das práticas psicológicas que reforçam a lógica da técnica sob a lógica da reflexão sobre as técnicas. A lógica da técnica nas práticas psicológicas constitui-se no campo da saúde pública quando se adaptam as políticas públicas ao rol de tecnologias da Psicologia, como apontam pesquisas realizadas pelo Centro de Referência Técnica em Psicologia e Políticas Públicas (CREPOP), em vez de as práticas psicológicas desterritorializarem-se pelas políticas públicas. Isso aponta para uma racionalidade das práticas psicológicas que ainda converge para a rede de saúde pública como mercado de trabalho, e não como forma efetivamente de incorporação das políticas públicas de saúde na formação em Psicologia (Spink, Bernardes, Santos, \& Gamba, 2007).

O dispositivo de publicização alarga as tecnologias psicológicas, no sentido de capturar as potências de vida que escapam às formas de subjetivação produzidas pela saúde pública. Articular-se ao campo da saúde coletiva cria a necessidade, nas práticas psicológicas, de invenção de novas tecnologias de trabalho. O coletivo é uma ameaça à racionalidade técnica das práticas psicológicas, na medida em que, como conjunto de forças, fragiliza as possibilidades de controle psicológico sobre a vida, quando por coletivo objetiva-se um conjunto heterogêneo de vetores de subjetivação que emergem da relação entre sujeito e cidadania, e não mais sujeito e privado. 
Assim, o coletivo não é um conceito-problema no campo psicológico, articulador de práticas psicológicas no que tange à incorporação do discurso da saúde coletiva como eixo transversal a toda formação (Macedo \& Dimenstein, 2009). Ao ser capturado por uma lógica mercadológica e privatista, ainda constitutiva da formação em Psicologia (Guareschi et al., 2010), o coletivo torna-se apenas outro modo de designação da população/pobreza e benesse social.

Ao constituírem-se como estratégia do dispositivo de publicização, as práticas psicológicas acabam por reforçar, ainda na atualidade, uma racionalidade da saúde pública em que esta não se trata de um direito universal, e sim de mercado de trabalho e benesse para a população desprovida de recursos privados, tanto no âmbito do fato psicológico - pobreza psíquica - quanto no âmbito de suportes sociais - pobreza econômica (Macedo \& Dimenstein, 2009). A saúde coletiva aparece como prática de resistência, provocando a construção de novas tecnologias, mas não ainda como fio condutor da formação em Psicologia.

\section{Referências}

Bernardes, A. (2006). Políticas da existência no campo da saúde: o público como um dispositivo (Tese de Doutorado, Universidade Católica do Rio Grande do Sul, Porto Alegre).

Bleger, J. (1984). Psico-Higiene e Psicologia Institucional. Porto Alegre: Artes Médicas.

Campos, G. W. S. (2009). Considerações sobre a arte e a ciência da mudança: revolução das coisas e reforma das pessoas: o caso da saúde. In S. Resende, M. E. Carvalho, \& S. Ferigato (Orgs.), Conexões: saúde coletiva e politicas de subjetividade (pp. 243-275). São Paulo: Aderaldo \& Rothschild.

Castel, R. (2003). Propriedad privada, propriedad social, propriedad de sí mismo. Rosario: Homo Sapiens.

Coimbra, C. (1995). Guardiães da Ordem: uma viagem pelas práticas psi no Brasil do "Milagre". Rio de Janeiro: Oficina do Autor.

Coimbra, C. (2002). Doutrina de segurança nacional e produção de subjetividade. In C. Rauter, E. Passos, \& R. B. Barros (Orgs.), Clínica e política: subjetividade e violação dos direitos humanos (pp. 25-38). Rio de Janeiro: Franco Basália e Tecorá.

Dimenstein, M. (1998). O psicólogo nas Unidades Básicas de Saúde: desafios para a formação e atuação profissionais. Estudos de Psicologia (Natal), 3(1), 53-81.

Foucault, M. (1987). Hermeneutica del sujeto. Madrid: La Piqueta.

Foucault, M. (1995a). Microfísica do Poder. Rio de Janeiro: Graal.
Foucault, M. (1995b). O sujeito e o poder. In H. Dreyfus \& P. Rabinow (Orgs.), Michel Foucault, uma trajetória filosófica: para além do estruturalismo e da hermenêutica (pp. 231-249). Rio de Janeiro: Forense.

Foucault, M. (1999). História da sexualidade I: a vontade de saber. Rio de Janeiro: Graal.

Foucault, M. (2000). Arqueologia do saber. Rio de Janeiro: Forense Universitária.

Foucault, M. (2002a). A loucura só existe em uma sociedade. In M. Foucault, Ditos e escritos I (pp. 162-164). Rio de Janeiro: Forense Universitária.

Foucault, M. (2002b). A Psicologia de 1850 a 1950. In M. Foucault, Ditos e escritos I (pp. 133-151). Rio de Janeiro: Forense Universitária.

Foucault, M. (2003). A “Governamentalidade”. In M. Foucault, Ditos e escritos IV (pp. 270-305). Rio de Janeiro: Forense Universitária.

Foucault, M. (2005). Em defesa da sociedade. São Paulo: Martins Fontes.

Guareschi, N., Dhein, G., Reis, C., Machry, D. S., \& Bennemann, T. (2010). A Psicologia e a formação do profissional da saúde para o SUS: um estudo a partir dos currículos de cursos de Psicologia do Rio Grande do Sul. In N. Guareschi, A. Scisleski, C. Reis, G. Dhein, \& M. A. Azambuja (Orgs.), Psicologia, formação, política e produção de saúde (pp. 29-53) Porto Alegre: EDIPUCRS.

Lei n. 8.080, de 19 de setembro de 1990. (1990, 20 de setembro). Dispõe sobre as condições para a promoção, proteção e recuperação da saúde, a organização e o funcionamento dos serviços correspondentes e dá outras providências. Diário Oficial da União. Recuperado de http://portal.saude.gov.br/saude/ legislação.

Macedo, J. P., \& Dimenstein, M. (2009). Psicologia e a produção de cuidado no campo do bem-estar social. Psicologia \& Sociedade, 21(3), 293-300.

Nascimento, C. (2004). Construindo processos de organização dos psicólogos em saúde pública. In C. Nascimento (Org.), Psicologia e políticas públicas (pp. 11-16). Porto Alegre: Conselho Regional de Psicologia/07.

Rose, N. (2001a). Inventando nossos eus. In T. Silva (Org.), Nunca fomos humanos: nos rastros do sujeito (pp. 137-204). Belo Horizonte: Autêntica.

Rose, N. (2001b). Como se deve fazer a história do Eu? Educação \& Realidade, 26(1), 33-57.

Spink, M. J. (2003). Psicologia social e saúde: práticas, saberes e sentidos. Petrópolis: Vozes.

Spink, M. J., \& Matta, G. C. (2007). A prática profissional psi na Saúde Pública: configurações históricas e desafios contemporâneos. In M. J. Spink (Org.), A psicologia em diálogo com o SUS: prática profissional e produção acadêmica (pp. 25- 51). São Paulo: Casa do Psicólogo.

Spink, M. J., Bernardes, J., Santos, L., \& Gamba, E. (2007). A inserção de psicólogos em serviços de saúde vinculados ao SUS: subsídios para entender os dilemas da prática e os desafios da formação profissional. In M. J. Spink (Org.), A psicologia em diálogo com o SUS: prática profissional e produção acadêmica (pp. 53-79). São Paulo: Casa do Psicólogo.

Anita Guazzelli Bernardes, doutora em Psicologia pela Pontifícia Universidade Católica do Rio Grande do Sul (PUCRS), é professora e pesquisadora no Programa de Pós-graduação em Psicologia da Universidade Católica Dom Bosco (UCDB). Endereço para correspondência: Rua Abrão Júlio Rahe, 884, casa 1, Centro, Campo Grande-MS. CEP: 79.010-010. Tel: (67) 8154-5256. E-mail: anitabernardes@ig.com.br Neuza Maria de Fátima Guareschi, PhD em Educação pela University of Wisconsin - Madson, é professora e pesquisadora no Programa de Pós-graduação em Psicologia Social e Institucional da Universidade Federal do Rio Grande do Sul (UFRGS). 